\title{
Subxiphoid Tube Pericardiostomy in the Management of Pericardial Effusion: Our Experience
}

\author{
Abubakar Umar ${ }^{1}$, , Salisu Ismail ${ }^{1}$, Usman Muhammad Sani ${ }^{2}$, Muawiya Usman Zagga ${ }^{3}$ \\ ${ }^{1}$ Cardiothoracic Surgery Unit, Department of Surgery, Usmanu Danfodiyo University/Usmanu Danfodiyo University Teaching Hospital, \\ Sokoto, Nigeria \\ ${ }^{2}$ Cardiology Unit, Department of Paediatrics, Usmanu Danfodiyo University/Usmanu Danfodiyo University Teaching Hospital, Sokoto, \\ Nigeria \\ ${ }^{3}$ Cardiology Unit, Department of Medicine, Usmanu Danfodiyo University Teaching Hospital, Sokoto, Nigeria
}

\section{Email address:}

drzuru@yahoo.com (A. Umar)

${ }^{*}$ Corresponding author

\section{To cite this article:}

Abubakar Umar, Salisu Ismail, Usman Muhammad Sani, Muawiya Usman Zagga. Subxiphoid Tube Pericardiostomy in the Management of Pericardial Effusion: Our Experience. International Journal of Cardiovascular and Thoracic Surgery. Vol. 5, No. 4, 2019 , pp. 64-68. doi: $10.11648 /$ j.ijcts.20190504.11

Received: June 16, 2019; Accepted: July 16, 2019; Published: September 24, 2019

\begin{abstract}
Introduction - There is minimal amount of fluid within the two layers of the pericardium. This serves to lubricate the layers preventing friction. Various disease processes can lead to increase in the amount of this fluid which cause haemodynamic compromise these patients. Various methods have been used to drain this fluid. We report our experience with subxiphoid tube pericardiotomy in the drainage of pericardial effusion. Material and Method - we reviewed case files of 30 patients that presented to us with pericardial effusion over a six-year period. Results - There were 19 males $(63.3 \%)$ and 11 females (36.7\%). Age range is between 2 yrs and 65 years with a mean of 27.3 yrs. Adult age group accounted for $25(83.3 \%)$ while paediatric age group was $5(16.7 \%)$. Predominant symptom was dyspnea and all patients had subxiphoid tube pericardiostomy for drainage. Majority of our patients (80\%) had tuberculosis as the cause of their effusion. Mortality was 3 $(10 \%)$ following the drainage but cause of death was progression of their disease. The was recurrence in one patient who had malignant effusion and was subsequently treated with pericardial window but later lost to follow up. Conclusion - Subxiphoid tube pericardiostomy still remains the main stay in the management of massive tuberculous pericardial effusion in our environment as it provides the opportunity to drain the fluid and take adequate fluid samples and tissue for diagnosis. Recurrence rate is also low.
\end{abstract}

Keywords: Pericardial Effusion, Subxiphoid, Pericardiostomy

\section{Introduction}

The normal pericardial sac contains $10-50 \mathrm{ml}$ of pericardial fluid which is an ultrafiltrate of plasma. It serves as a lubricant between the two layers thereby preventing friction. Pathologies that cause inflammation of the pericardium can lead to exudative pericardial effusion while on the alternative decreased reabsorption due to general increase in systemic venous pressure as a result of congestive cardiac failure or pulmonary hypertension may lead to accumulation of transudative pericardial fluid [1-4]. There are various classifications of pericardial effusion. It can be according to onset, which can either be acute, subacute or chronic, according to distribution which can be circumferential or loculated, according to its effect on the patients haemodynamics which can be none, cardiac tamponade, effusive constrictive, according to composition which can be exudative, transudative, blood or rarely air, by its size which is a form of semiquantitative assessment on echocardiography, it can be $<10 \mathrm{~mm}$ (small or minimal), 10$20 \mathrm{~mm}$ (moderate) and $>20 \mathrm{~mm}$ (large or massive). Acute, circumferential, transudative, small size or minimal without any haemodynamic effects can be managed conservatively by treating the underlying cause or with medications [5-8]. 
whereas chronic, large with haemodynamic compromise will require drainage which can either be by echocardiography guided pericardiocentesis, subxiphoid tube pericardiostomy, pericardial window through a left thoracotomy or via video assisted thoracoscopic surgery (VATS) [9-12].

We report our experience of using subxiphoid tube pericardiostomy to treat pericardial effusion.

\section{Materials and Methods}

We reviewed the case files of 30 patients that presented to us or referred to our unit with pericardial effusion who underwent subxiphoid tube pericardiostomy for the treatment of symptomatic pericardial effusion over a six-year period (2013-2018).

Echocardiography was used for both diagnosis and determining the amount of pericardial effusion whether small, moderate or massive. It was also used to determine whether its clear fluid or there are debri and fibrinoid strands. Features of cardiac tamponade were determined both clinically and confirmed by echocardiography. Clinically the presence of tachycardia, dyspnea or tachypnea with clear chest examination findings or signs of increased systemic venous pressure like hypotension or pulsus paradoxus. Two dimensional echocardiographic findings of early diastolic collapse of the right ventricle, late diastolic collapse of the right or left atrium and plethora of the inferior vena cava in the presence of pericardial effusion. Doppler echocardiographic finding of tamponade were major increases of tricuspid E flow and major decreases of mitral E flow during inspiration compared with apnoea (with the reverse in expiration).

Basic investigations like packed cell volume, urinalysis and electrolyte, urea and creatinine were done for all the patients. All the patients were operated in the unit's operating theatre. Patients were placed either in $30^{\circ}$ or $45^{\circ}$ head-up. This is because all patients were symptomatic and could not lie flat. Local anaesthesia, local anaesthesia with sedation or general anaesthesia were the forms of anaesthesia used depending on the tolerance of the patient. Local anaesthesia or local anaesthesia with sedation were administered after patient was cleaned and draped while general anaesthesia was administered before cleaning and draping. A subxiphoid incision was made extending slightly above the xiphoid down to the linea alba. The xiphoid was exposed and excised. Dissection of the subxiphoid space was carried out through the retrosternal space. Pre-pericardial fat was dissected to expose the anterior pericardium. Test aspiration was carried out to confirm the presence of fluid and also take samples for microscopy, culture and sensitivity as well as cytology and biochemistry. Pericardium was pulled after passing a $2 / 0$ silk on it, a $2-5 \mathrm{~cm}$ rim of the pericardium was excised for histology and pericardial fluid drained with the aid of a sucker placed within the pericardial space. Digital exploration of the pericardial cavity was carried out in order to break loculations and fibrinoid strands so as to facilitate drainage. Appropriate size chest tube was placed through a separate stab incision because we don't have a pericardial tube. Tube was anchored and connected to an underwater seal drainage system. Pericardial opening was not closed but subxiphoid wound was closed in layers. Patients were transferred to the ward where they receive their postoperative care. Tube was removed when drainage became minimal and serous. All patients were followed up in our out-patient clinic.

\section{Results}

The records of 30 patients were reviewed. There were 19 males $(63.3 \%)$ and 11 females (36.7\%). Age range is between 2 yrs and 65 yrs with a mean of 27.3 yrs. Adult age group accounted for $25(83.3 \%)$ while paediatric age group was $5(16.7 \%)$ see table 1 . All patients were symptomatic at the time of presentation. All patients presented with dyspnea as the predominant symptom. Twenty-six patients $(86.7 \%)$ presented with massive effusion, while $2(7.7 \%)$ had moderate effusion and $2(7.7 \%)$ had minimal effusion see table 1. Two patients were HIV positive, they also had tuberculosis and all were already on treatment for both. Of two that had minimal effusion, one had traumatic haemopericardium while the other had minimal effusive constrictive pericarditis. Tube pericardiostomy was done for all the patients. Additional procedures were carried out in 2 (7.7\%) patients, one had incision and drainage of right thigh pyomyositis and the other had drainage of left sided massive pleural effusion. Local anaesthesia was used for 19 (63.3\%) patients, local anaesthesia with sedation in $2(7.7 \%)$ and general anaesthesia in $9(30 \%)$. All patients were operated on emergency basis. Drainage volume was between $180 \mathrm{mls}$ to $2000 \mathrm{mls}$ and average postoperative drainage volume was $350 \mathrm{mls}$ and average postoperative drainage period was 4.5 days. The highest drainage volume was obtained from a patient with massive purulent tuberculous pericarditis and the lowest was from a patient with traumatic haemopericardium. Fluid was purulent in $15(50 \%)$, haemorrhagic in $7(23.3 \%)$ and serous in $8(26.7 \%)$. Histopathological examination of the pericardial fluid revealed malignant cells in $2(7.7 \%)$ patients. Twenty four $(80 \%)$ of our patients had histological features of tuberculous pericarditis and were subsequently commence on antituberculous drugs. Duration of hospitalization was between 5-15 days. Overall 30-day mortality was 3 (10\%). The 3 patients died from the progression of their primary disease process. One patient $(3.33 \%)$ whose cytology revealed malignant cells but had recurrence. He subsequently had pericardial window but was lost to follow up.

Table 1. Demographic characteristics of patients.

\begin{tabular}{lll}
\hline Age & Number & Percentage (\%) \\
\hline $0-10$ & 2 & 6.67 \\
$11-20$ & 3 & 10.00 \\
$21-30$ & 9 & 30.00 \\
$31-40$ & 7 & 23.33 \\
$41-50$ & 6 & 20.00 \\
$51-60$ & 2 & 6.67 \\
\hline
\end{tabular}




\begin{tabular}{lll}
\hline Age & Number & Percentage (\%) \\
\hline$>60$ & 1 & 3.33 \\
Total & 30 & 100 \\
Sex & & \\
Male & 19 & 63.33 \\
female & 11 & 36.67 \\
Total & 30 & 100 \\
Volume of fluid drained & & \\
intraoperatively & & \\
$<500$ & 2 & 6.67 \\
$500-1000$ & 2 & 6.67 \\
$>1000$ & 26 & 86.66 \\
Total & 30 & 100 \\
\hline
\end{tabular}

\section{Discussion}

The demography of our patients shows slight male preponderance which is in keeping with reports from other authors. Majority of our patients were adults Patients with massive pericardial effusion with cardiac tamponade. These patients usually presents to the emergency room requiring urgent drainage of the fluid. In our series, there is male preponderance which is what obtains in most studies without any statistically significant difference [7, 13-14]. Dyspnea was the predominant symptom in our patients and majority of our patients presented in tamponade which has been reported as the commonest mode of presentation in patients with massive pericardial effusion or posttraumatic acute haemopericardium $[1,4,15-16]$. This is always the case in our environment because majority of patients will only present when symptoms are unbearable. Over $80 \%$ of our patients presented with massive effusion which can be an explanation for the commonest presenting symptoms. Other studies reported massive effusion to account for $40-60 \%$ of their series [7, 17-19]. Late presentation in our series can account for the massive nature of the fluid. Two patients had minimal effusion, one was as a result of trauma which resulted in haemopericardium and features of tamponade. Patients with trauma leading to pericardial collection present early because of rapid accumulation within a tough fibrous pericardium that cannot suddenly yield to rapid increase in intrapericardial pressure [20-23]. Two of our patient were HIV positive and they presented with massive effusion and were on antiretroviral and anti-tuberculous drugs at the time of presentation. The association between massive effusion in patients with tuberculosis and HIV infection has been reported [24-27].

Pericardiocentesis has been shown to provide temporary relieve in this patients [28-30]. However, there is increased incidence of complications which include dysrhythmias, coronary artery puncture or aneurysm, haempthorax, pneumothorax, left internal mammary puncture or aneurysm, pneumopericardium, hepatic artery injury, recurrence, false negative aspiration (clotted blood in the pericardium), false positive aspiration (intracardiac aspiration). Complication rate is about $4-40 \%$ [31-33]. The ideal procedure for drainage of pericardial fluid should have the following characteristics: easy to perform, there should be minimal morbidity and mortality, ensure complete and permanent drainage of the fluid, should have infrequent recurrences, and provide sufficient tissue for histology, sufficient fluid for cytological, and microbiology for diagnosis of the cause of the effusion. Percutaneous pericardioscopy and subxiphoid drainage are the two procedures that can meet the above criteria. Pericardiocentesis can only provide fluid for cytological and microbiological examinations. Tube pericardiostomy was done for all our patients. All our patients were relieved of their symptoms and samples were taken for further diagnostic work-up for our patients. Over $60 \%$ of our patients had their procedure performed under local anaesthesia which has been reported as the preferred from of anaesthesia for this procedure. Becit et all and other reported that over $90 \%$ of their patients had their procedure done using local anaesthesia [7, 34, 35]. All the children in our series had drainage under general anaesthesia. This is because they are not likely to cooperate. Two of our adult patients had a combination of local anaesthesia and sedation. The procedure was commenced with local anaesthesia and they were unable to tolerate and could not cooperate as such had to be sedated. Allen et al combined local anaesthesia and intravenous sedation in $48 \%$ of their patients [12]. General anaesthesia was used in $30 \%$ of our patients. All our paediatric patients were operated using general anaesthesia. Pericardial biopsy was taken in all our patients, which is why this procedure is far superior to pericardiocentesis. The largest volume we drained was from a patient with tuberculous pericarditis and majority of our patient's histology results revealed tuberculous pericarditis [36-38]. This is said to be the commonest cause of large pericardial effusion followed by viral and idiopathic in our environment [39], many authors have reported instillation of intrapericardial sclerosant to cause symphysis of parietal and visceral pericardium to prevent recurrence [40-42]. It is not our policy to inject sclerosant into the pericardial space in order to close the pericardial space because of the reported complication rate and recurrence that is up to $45 \%$ [43-44]. We are concern about the long-term complication of constrictive pericarditis which has been reported as the major drawback of this procedure. Complication rate of this procedure was reported at $26.7 \%[45,46]$. Since the primary pathology in majority of our patients was tuberculousis, following administration of anti-tuberculous drugs after, there was no recurrence in these group of patients.

\section{Conclusion}

Majority of our patients present with dyspnea as a result of massive pericardial effusion. Subxiphoid tube pericardiostomy still remains the main stay in the management of massive pericardial effusion in our environment as it provides the opportunity to drain the fluid and take adequate fluid samples and tissue for diagnosis. Tuberculosis still remains the major cause of pericardial effusion. Following this procedure, there is instant relieve of symptom following this intervention and recurrence rate is also low. 


\section{References}

[1] Imazio M, Adler Y. Management of pericardial effusion. Eur Heart J 2013; 34: 1186-1197.

[2] Little WC, Freeman GL. Pericardial disease. Circulation 2006; 113: 1622-32.

[3] Sagristà-Sauleda J, Mercé AS, Soler-Soler J. Diagnosis and management of pericardial effusion. World J Cardiol 2011; 3: 135-43.

[4] Kesieme EB, Okokhere PO, Iruolagbe CO, Odike A, Owobu C, Akhigbe T. Surgical Management of Massive pericardial effusion and predictors for development of constrictive pericarditis in a resource limited setting. Advances in Medicine. 2016: 1-5

[5] Weitzman LB, Tinker WP, Kronzon I, Cohen ML, Glassman E, Spencer FC. The incidence and natural history of pericardial effusion after cardiac surgery-an echocardiographic study. Circulation 1984; 69: 506-511.

[6] Imazio M, Mayosi BM, Brucato A, Markel G, Trinchero R, Spodick DH, Adler Y. Triage and management of pericardial effusion. J Cardiovasc Med (Hagerstown) 2010; 11: 928-935.

[7] Becit N, Ozyazicioglu A, Ceviz M, et al. Clinical experience with subxiphoid pericardiostomy in the management of pericardial effusions: a study of 240 cases. J Int Med Res 2003; 31: 312-7.

[8] Maisch B, Seferovic PM, Ristic AD, et al. Guidelines on the diagnosis and management of pericardial diseases. Eur Heart J 2004; 25: 587-610.

[9] Imazio M, Brucato A, Cumetti D, Trinchero R. Corticosteroids for recurrent peri- carditis: high versus low doses: a nonrandomized observation. Circulation 2008; 118: $667-671$.

[10] Imazio M. Pericardial involvement in systemic inflammatory diseases. Heart 2011; 97: 1882-1892.

[11] Lindenberger $M$, Kjellberg $M$, Karlsson E, et al. Pericardiocentesis guided by 2-D echocardiography: the method of choice for treatment of pericardial effusion. J Intern Med 2003; 253: 411-7.

[12] Allen KB, Faber LP, Warren WH, et al. Pericardial effusion: subxiphoid pericardiostomy versus percutaneous catheter drainage. Ann Thorac Surg 1999; 67: 437-40.

[13] Uddin J, Singh MP, Mehdi MD. Study of etiological and clinical profile of pericardial effusion in a tertiary care hospital in Kosi region of Bihar India. Int J Adv Med. 2016; 3 (3): 514-518.

[14] Chen R, Shen T, Tsai K, Hu C (2016) Pericardial window operation for malignant pericardial effusion may have worse outcomes for lung cancer than the other cancers. Research Ideas and Outcomes 2: e8758. doi: 10.3897/rio.2.e8758.

[15] Roy CL, Minor MA, Brookhart MA, Choudhry NK. Does this patient with a pericardial effusion have cardiac tamponade? JAMA 2007; 297: 1810-1818.

[16] Sugimoto JT, Little AG, Ferguson MK, et al. Pericardial window: mechanisms of efficacy. Ann Thorac Surg 1990; 50: $442-5$.
[17] Sagristà-Sauleda J, Mercé J, Permanyer-Miralda G, SolerSoler J. Clinical clues to the causes of large pericardial effusions. Am J Med 2000; 109: 95-101.

[18] Kil UH, Jung HO, Koh YS, et al. Prognosis of large, symptomatic pericardial effusion treated by echo-guided percutaneous pericardiocentesis. Clin Cardiol 2008; 31: 5317.

[19] Colombo A, Olson HG, Egan J, Gardin JM. Etiology and prognostic implications of a large pericardial effusion in men. Clin Cardiol. 1988; 11: 389-94.

[20] Corey GR, Campbell PT, Van Trigt P, Kenney RT, O’Connor CM, Sheikh KH, Kisslo JA, Wall TC. Etiology of large pericardial effusions. Am J Med 1993; 95: 209-213.

[21] Spodick DH. Acute cardiac tamponade. N Engl J Med 2003; 349: 684-690.

[22] Reuter H, Burgess LJ, Doubell AF. Epidemiology of pericardial effusions at a large academic hospital in South Africa. Epidemiol Infect 2005; 133: 393-399.

[23] Saito Y, Donohue A, Attai S, Vahdat A, Brar R, Handapangoda I, Chandraratna PA. The syndrome of cardiac tamponade with 'small' pericardial effusion. Echocardiography 2008; 25: 321-327.

[24] U. Abubakar, PO Adeoye, OA Adebo, VO Adegboye, E Kesieme and EK Okonta. Pattern of Pericardial Diseases in HIV positive patients as seen in University College Hospital Ibadan, Nigeria. The southern African Journal of HIV Medicine. 2011: 25-26.

[25] Cegielski JP, Ramiya K, Lallinger GJ, Mtulia IA, Mbaga IM. Pericardial disease and human immunodeficiency virus in Dar es Salaam, Tanzania. Lancet. 1990; 335: 209-212.

[26] Stotka JL, Good CB, Downer WR, Kapoor WN. Pericardial effusion and tamponade due to Kaposi's sarcoma in acquired immunodeficiency syndrome. Chest. 1989; 95: 1359-1361.

[27] Sunderam G, McDonald RJ, Maniatis T, Oleske J, Kapila R, Reichman LB. Tuberculosis as a manifestation of the acquired immunodeficiency syndrome (AIDS). JAMA. 1986; 256: 362-366.

[28] Saltzman AJ, Paz YE, Rene AG, Green P, Hassanin A, Argenziano MG, et al. Comparison of surgical pericardial drainage with percutaneous catheter drainage for pericardial effusion. J Invasive Cardiol. 2012 Nov. 24 (11): 590-3.

[29] Akyuz S, Zengin A, Arugaslan E, et al. Echo-guided pericardiocentesis in patients with clinically significant pericardial effusion: outcomes over a 10 -year period. Herz. 2015 Apr. 40: 153-9.

[30] Callahan JA, Seward JB. Pericardiocentesis Guided by TwoDimensional Echocardiography. Echocardiography. 1997 Sep. 14 (5): 497-504.

[31] Fitch MT, Nicks BA, Pariyadath M, McGinnis HD, Manthey DE. Videos in clinical medicine. Emergency pericardiocentesis. N Engl J Med. 2012 Mar 22. 366 (12): e17.

[32] Salem K, Mulji A, Lonn E. Echocardiographically guided pericardiocentesis - the gold standard for the management of pericardial effusion and cardiac tamponade. Can J Cardiol. 1999 Nov. 15 (11): 1251-5. 
[33] Tsang TS, Freeman WK, Barnes ME, et al. Rescue echocardiographically guided pericardiocentesis for cardiac perforation complicating catheter-based procedures. The Mayo Clinic experience. J Am Coll Cardiol. 1998 Nov. 32 (5): $1345-50$.

[34] Colak A, Becit N, Kaya U, Ceviz M, Cocak H. Treatment of pericardial effusion through subxiphoid tube pericardiostomy and computerized tomography-or Echocardiography-guided catheter drainage methods. Braz J Cardiovasc Surg 2019; 34 (2): 194-202.

[35] Park CY1, McGonigle NC Single-Port Thoracoscopic Pericardial Window Under Local Anesthesia Innovations. 2018; 13 (1): 62-4.

[36] Montgomerie JZ, Lewis AJ, Fiala M, et al. Pericarditis. West J Med 1975; 122: 295-309.

[37] Quale JM, Lipschik GY, Heurich AE. Management of tuberculous pericarditis. Ann Thorac Surg 1987; 43: 653-5.

[38] Chen Y, Brennessel D, Walters J, et al. Human immunodeficiency virus-associated pericardial effusion: report of 40 cases and review of the literature. Am Heart $\mathrm{J}$ 1999; 137: 516-21.

[39] Noubiap JJ, Agbor VN, Ndoadoumgue AL, et al. Epidemiology of pericardial diseases in Africa: a systematic scoping review. Heart 2019; 105: 180-188.

[40] Girardi LN, Ginsberg RJ, Burt ME. Pericardiocentesis and intrapericardial sclerosis: effective therapy for malignant pericardial effusion. Ann Thorac Surg. 1997 Nov; 64 (5): $1422-7$.

[41] Figoli F, Zanette ML, Tirelli U, Sorio R, Lestuzzi C, Urso R, Monfardini S, D'Incalci M. Pharmacokinetics of VM 26 given intrapericardially or intravenously in patients with malignant pericardial effusion. Cancer Chemother Pharmacol. 1987; 20: 239-242.

[42] Markman M, Howell SB. Intrapericardial instillation of cisplatin in a patient with a large malignant effusion. Cancer Drug Deliv. 1985; 2: 49-52.

[43] Davis S, Rambotti P, Grignani F. Intrapericardial tetracycline sclerosis in the treatment of malignant pericardial effusion: an analysis of thirty-three cases J Clin Oncol. 1984: 2 (631-6).

[44] Shepherd FA, Morgan C, Evans WK, Ginsberg JF, Watt D, Morphy K. medical management of malignant pericardial effusion by tetracycline sclerosis. Am J Cardiol. 1987: 60; 1161-1166.

[45] Kaira K, Takise A, Kobayashi G, Utsugi M, Horie T, Mori T et al. management of malignant pericardial effusion with instillation of mitomycin $\mathrm{C}$ in non-small cell lung cancer. Jopn J Clinc Oncol. 2005: 35; 57-60.

[46] Schusler R, Meyerson SL. Pericardial Disease Associated with Malignancy, Current Cardiology Reports 2018: 20 (92); 1040-5. 